\title{
BENTUK-BENTUK PETULANGAN DALAM UPACARA NGABEN DITINJAU DARI SUDUT KESENIRUPAAN DI BALI
}

\author{
I Dewa Made Pastika ${ }^{1}$
}

\begin{abstract}
The Art of sarcophagus has been known in Bali since ancient up to now in relationship with a cremation ceremony called "Ngaben" or "Pelebon". Its function is as a plase for the dead body during cremation in order that the dead body is protected and its ash can be easily collected after the cremation Phylosophically, sarcophagi whith are shape of animals have. a meaning of a pach into the heaven for the soul of the cremated body. Besides, if we view them from the art aspect, they hava special artistic velues and special beauty which become an important cultural asset to attract tourist who want to watch them.

Ornaments of the sarcophagi generally used in Bali, are taken from animals such as lion, deer, akin of dragon, gedarba, tiger, and kinds of fish. The shaped sarcophagi are adorned with carved ornaments or with cutouts which are stuck on them and made from paper with various carving motif and coloured-catton thread for example: takep pala, takep piah, pengampad, badong, bottems cover ornament, fire tongue, "gunala", "karang guak", "dure ". Ornaments carved in various motif such as "patra punggel”, "patra sari”, mas-masan, "cracap", patra cina " and other " kekarangan ". Comparison elements have important role on the beauty of sarcophagus work such as the comparison between the height and the length of the sarcophagus. Sarcophagi not only have special religious meaning, but olso they have high artistic value which should be developed in the future.
\end{abstract}

Key Word : Sarcophagus, Cremation, Ceremony

Sejak dahulu Pulau Bali telah terkenal dengan keindahan alamnya, adatistiadatnya, kebudayaan pada umumnya dan kesenian pada khususnya. Kesenian yang sangat erat kaitannya dengan Agama Hindu dalam perwujudannya meliputi seni lukis, seni patung, seni tari, seni sastra, seni musik (gambelan). Pada mulanya seni diciptakan untuk kepentingan upacara agama dengan fungsi pemujaan, misalnya: seni lukis berupa simbul yang dipuja dan seni patung berbentuk arca lingga dalam perwujudan tertentu bersifat simbolis

${ }^{1}$ I Dewa Made Pastika adalah Dosen pada Jurusan Kriya Seni Fakultas Seni Rupa dan Desain Institut Seni Indonesia Denpasar. 
bertujuan untuk alat konsentrasi pemujaan kepada Betara-Betari (Parisada, 1978:3). Sedangkan seni suara dan seni tari dipentaskan dalam upacara yadnya. Hal ini tidak jauh berbeda dengan kepercayaan bangsa lain, yang menurut pendapat Dr. Kuhn dalam buku Pengertian Seni mengemukakan bahwa lukisan-lukisan itu tidak hanya mempunyai nilai estetis tetapi seperti halnya lukisan dari abad pertengahan di Eropah, lukisan-lukisan itu juga memiliki kepentingan dalam agama atau dalam pengalaman magis (Herbert Read : 5).

Di Bali kesenian itu lahir dan berkembang dengan subur yang saling tunjang-menunjang dengan kehidupan beragama terwujud dalam pelaksanaan Panca Yadnya, dan salah satu diantaranya adalah, Pitra Yadnya. Dalam melaksanakan upacara Pitra Yadnya dalam hal ini upacara ngaben, dibuat sarana-sarana upacara seperti: wadah dan petulangan selain banten sebagai sarana utamanya. Wadah dan petulangan dihiasi dengan bermacam-macam hiasan dari kertas, kain, kapas, benang berwarna-warni merupakan media yang baik dalam mengungkapkan rasa keindahan.

Petulangan berasal dari kata tulang atau galih atau jenasah yang akan diupacarai. Kata tulang mendapat awalan pe dan akhiran an, menjadi petulangan. Jadi petulangan berarti suatu alat atau tempat tulang atau jenasah pada pembakaran mayat. Petulangan sebagai tempat pembakaran mayat umumnya berbentuk binatang-binatang tertentu yang bersifat simbolis. Ada pula berbentuk peti sederhana (gerombong polos) yang diberi kaki dan ekor yang disebut petulangan bentuk tabla. Dalam keadaan darurat petulangan dibuat dari batang pisang, disusun demikian rupa, dilengkapi pula dengan bentuk kepala sehingga menyerupai bentuk binatang.

Kebiasaan membuat petulangan untuk kelengkapan sarana upacara ngaben di Bali, telah diwariskan secara turun temurun oleh nenek moyang dari jaman dahulu sampai sekarang. Walaupun telah banyak para ahli menulis tentang upacara ngaben dengan segala peralatannya, namun belum banyak yang meninjau dari unsur-unsur seni rupanya.

Bertitik tolak dari betapa pentingnya arti petulangan baik fungsi dan estetisnya, kajian petulangan ini dilihat dari unsur-unsur seni rupanya yaitu pada: bentuk, proporsi, anatomi, hiasan serta pewarnaan petulangan dalam berbagai bentuk. Diharapkan kajian ini dapat meningkatkan nilai estetis bentuk-bentuk petulangan dalam upacara ngaben dan dapat memuaskan bagi masyarakat luas.

\section{TINJAUAN SEJARAH}

Sejak jaman purba nenek moyang kita telah mengenal cara-cara penguburan mayat seperti sarkopagus. Sarkopagus adalah alat untuk penguburan mayat yang bentuknya seperti palung tetapi mempunyai tutup di atasnya. Kubur batu yang sebetulnya tidak berbeda dengan peti mayat dari batu, keempat dindingnya papan batu, begitu pula alas dan atapnya dari pa- 
pan batu (Goris:23). Cara-cara penguburan mayat dalam sarkopagus berkembang dalam bentuk penguburan jaman sekarang. Kemudian ditingkatkan sesuai dengan perkembangan kerohanian dengan masuknya agama Hindu di Indonesia. Kita mengenal candi-candi yang pada masa pengaruh Hindu didirikan, tidak lain fungsinya untuk menyimpan abu jenasah para raja pada jaman tersebut. Terdapat kata abu adalah keterangan yang menunjukkan bahwa pembakaran mayat sudah biasa dilakukan. Kebiasaan ini berlangsung terus, disempurnakan pada masa datangnya pengaruh Kerajaan Majapahit dari Jawa Timur.

Menurut lontar Babad Dalem Katiagan, milik I Ketut Rinda dikatakan bahwa pada suatu waktu Raja Watu Renggong bertanya pada Hyang Nirartha, tentang mana yang lebih mulia, antara swadharma seorang kesatria sebagai raja dengan swadharma seorang brahmana sebagai pendeta. Dari pertanyaan tersebut jawaban yang diperoleh bahwa keduanya adalah sama utamanya, hanya jalan yang berbeda. Kalau kebrahmanaan menjalankan ajaran kepanditaan, kerohanian (dharma), sedangkan kesatria menjalankan pemerintahan dan kesejahtaraan rakyat serta kekuasaan dalam pemerintahan.

Dengan penjelasan itu, maka raja Dalem Watu Renggong memilih swadarma kesatria sebagai seorang raja yang memiliki rakyat banyak untuk mengusung jenasahnya kelak setelah meninggal. Untuk itu beliau meminta dibuatkan petulangan berbentuk lembu dan bade sebagai tempat usungan jenasah. Dari penjelasan di atas maka bade dan petulangan sebagai peralatan upacara "ngaben" (pembakaran jenasah) baru dikenal setelah pemerintahan Dalem Watu Renggong yang memerintah di Gelgel.

\section{FUNGSI PETULANGAN DALAM UPACARA NGABEN}

Fungsi petulangan dalam upacara ngaben sangat erat kaitannya dengan kepercayaan nenek moyang terhadap binatang-binatang yang dianggap suci, keramat, memiliki kekuatan dan dijadikan lambang-lambang tertentu. Seperti kerbau yang terdapat diseluruh tanah air dipandang sebagai lambang kesuburan, sebagai penolak roh-roh jahat dan sebagai tunggangan roh leluhur di akhirat (Van Der Hoop, 1949:136). Di daerah Toraja, Sulawesi pada waktu peralatan penjenasahan banyak kerbau dipotong, satu di antara kerbau tersebut dianggap sebagai kendaraan orang yang meninggal di akhirat. Hiasan rumah masyarakat Toraja dibuat dari kayu berbentuk kerbau. Hal ini ada persamaan dengan petulangan berbentuk lembu pada upacara ngaben di Bali. Binatang kerbau mempunyai arti yang sangat penting dalam upacara penjenasahan (Van Der Hoop, 1949:138).

Kepercayaan terhadap binatang menjangan yang disucikan, digambarkan dalam bangunan bagian muka dari Menjangan Seluang Mospait, rumah suci untuk dewa Mojopahit dalam kuil di Pura Desa Singaraja Bali, suatu peringatan terhadap perpindahan orang Hindu Jawa ke Bali setelah jatuh- 
nya Majapahit (Van Der Hoop, 1949:156). Di Bali kepercayaan terhadap binatang lembu sebagai binatang yang disucikan. Lembu dipercaya sebagai wahananya Dewa Siwa. Dewa Brahma dipandang sebagai dewa pencipta segala yang ada, wahananya binatang singa. Sedangkan Dewa Wisnu berfungsi sebagai pemelihara, wahananya naga. Binatang-binatang tersebut disucikan, dihormati, sebagaimana menghormati dewa-dewa dengan manifestasinya masing-masing.

Menurut Drs. Ida Bagus Purwita dari Griya Yang Batu Denpasar, (sekarang sulinggih) meninjau dari segi filosofinya bahwa perwujudan petulangan dengan motif binatang, mengandung arti sebagai petunjuk jalan ke sorga bagi roh orang yang telah meninggal. Binatang nama lainnya sattwa terdiri dari kata sat dan twa. Sat berarti inti (esensiil); twa berarti sifat. Jadi sattwa berarti bersifat esensiil dalam agama ialah Sang Hyang Widhi (Tuhan Yang Maha Esa). Dengan menggunakan petulangan berbentuk binatang, mengandung maksud agar roh secepatnya menuju Siwa Loka (Ida Sang Hyang Widhi Wasa). Sedangkan binatang tersebut sebagai perwujudan petulangan sesuai dengan keyakinan dan kepercayaan umat terhadap kesucian dari binatang tersebut.

Penggunaan petulangan dengan bentuk binatang ditentukan oleh sifat perwatakan serta kewajiban seseorang dalam masyarakat. Menurut lontar awig-awig Denpasar milik Mangku Jero Kuta, Jagat Wewengkon Badung pemakaian bentuk petulangan diatur menurut susunan kasta yang ada di Bali yaitu sebagai berikut: Bagi wangsa sudra jadma memakai petulangan bentuk gedarba atau bentuk macan, atau bentuk gajah mina. Sang Aria memakai petulanggan berbentuk menjangan. Sang Kesatria memakai petulangan bentuk singa. Brahmana Welaka memakai petulangan bentuk lembu hitam dan Pendeta memakai petulangan bentuk lembu putih. Dengan demikian fungsi petulangan adalah sebagai berikut.

a. Dalam pengertian umum petulangan berfungsi sebagai tempat membakar jenasah dan secara spiritual, berfungsi sebagai pengantar roh ke alam roh (sorga atau neraka) sesuai dengan hasil perbuatan di dunia.

b. Menunjukkan jenis sekte seseorang yang dianut leluhurnya.

c. Menunjukkan watak dan kewajiban seseorang dalam masyarakat.

d. Menunjukkan rasa bakti dan penghormatan terhadap dewa-dewa, karena dengan meniru wahananya sebagai sarana upacara. Maka seolah-olah lebih dekat dengan Ida Sang Hyang Widhi.

e. Sebagai pernyataan rasa seni yang menimbulkan kepuasan batin bagi yang diupacarai, orang yang menyelenggarakan upacara, seniman (sangging) yang mengerjakannya, dan masyarakat luas yang menikmatinya.

\section{BENTUK-BENTUK DAN JENIS PETULANGAN}

Ada banyak pendapat dari berbagai sumber dan informan mengenai bentuk dan jenis petulangan dalam upacara ngaben, yaitu : 
Menurut lontar Yama Tatwa milik Pedanda Gede Manuaba, dari Griya Anyar Padang Tegal Ubud, Gianyar menyebutkan petulangan berbentuk: naga, lembu ,singa, macan dan tabla. Sedangkan lontar Awig-awig Yama Purana Tatwa tertulis petulangan berbentuk: gedarba, macan, gajah mina, menjangan, lembu dan singa. Menurut A.A. Ketut Anggara (alm) dari Banjar Belong Denpasar menjelaskan petulangan berbentuk: lembu hitam, lembu putih, singa, gajah mina, naga kaang. Menurut Ida Bagus Candra (alm) dari Kesiman menjelaskan petulangan berbentuk: lembu, macan, singa, singa kaang, naga kaang, gedarba, gajah mina dan sudang-sudangan. Berdasarkan uraian di atas dapat disimpulkan bahwa jenis atau bentukbentuk petulangan sebagai berikut.

1. Petulangan lembu putih, dan lembu hitam idealnya binatang lembu dipakai oleh orang yang dipandang suci seperti para pendeta, para pemangku (lembu, putih) dan lembu hitam oleh kesatria dan brahmana welaka.

2. Bentuk petulangan singa, bentuknya idealis singa, warnanya merah tua bersayap. Umumnya dipakai oleh raja-raja dan warga pasek.

3. Petulangan bentuk naga kaang, ialah bentuk idealis naga dikombinasikan dengan ikan, berkepala naga dan badan bersisik ikan dan bersayap. Kaki sebagai kaki lembu dan bersisik pada bagian belakang kaki, dipakai oleh para arya sentong, sekte wisnu.

4. Bentuk petulangan gedarba idealnya binatang beruang, berwarna hitam. Kaki bertanduk (tegil), dipakai oleh kula wangsa (orang kebanyakan).

5. Bentuk petulangan gajah mina idealnya kombinasi dari binatang gajah dan ikan berupa binatang purba sejenis ikan berkepala gajah, dipakai oleh golongan wesia.

6. Bentuk petulangan singa kaang, berbentuk singa, kaki bagian belakang bertanduk dan bersisik seperti sisik ikan dipakai oleh pasek baliaga dan pasek pulasari.

7. Bentuk petulangan menjangan, idealnya binatang menjangan bertanduk bercabang-cabang, dipakai oleh sang arya

8. Bentuk petulangan macan (harimau), idealnya binatang harimau, warna merah dan kulit belang, dipakai oleh pasek pulosari, pande.

9. Bentuk petulangan sudang-sudangan, berbentuk seperti ikan dan kulit bersisik, dipakai oleh para nelayan di daerah tepi pantai.

10. Bentuk petulangan tabla, berbentuk peti biasa, berkaki empat sebagai penyangga. Warnanya putih simbul kesucian, dipakai oleh mereka yang dipandang suci.

\section{Bentuk dan Proporsi Anatomi}

Secara umum bentuk petulangan terdiri dari bagian-bagian kepala, badan, kaki dan ekor. Bentuk akan mencapai kesempurnaan bila ada perbandingan yang selaras antara kepala, badan, kaki dan lainnya. Secara umum perbandingan ditentukan dari penampang kayu untuk kepala petulangan. Misalnya penampang kayu untuk kepala sebesar: 40 x $40 \mathrm{~cm}$, maka panjang badan untuk mendapatkan proporsi yang baik adalah $5 \times 40 \mathrm{~cm}=200 \mathrm{~cm}$. 
Tinggi petulangan diukur dari punggung bagian depan sampai alas sama dengan panjang badannya. Panjang leher sama dengan panjang dagu. Tinggi tanduk (untuk petulangan bentuk lembu) sama dengan panjang kepala. Telinga tingginya sama dengan jarak dari mata sampai pangkal telinga. Tinggi ekor sama dengan tinggi kepala. Perbandingan bagian bentuk kepala lembu ditentukan dari penampang balok kayu yang disediakan untuk kepala. Ukuran kayu antara panjang, lebar dan tinggi berbanding: $2: 1$ : 1 . Dari bidang samping kayu ditarik garis pertolongan yaitu: dua garis sejajar yang membujur dan dua garis sejajar yang melintang, membagi bidang-bidang yang sama. Dari garis pertolongan tersebut ditentukan letaknya mata, tanduk, telinga, mulut serta hidungnya. Mata letaknya pada perpotongan garis yang melintang di atas dengan garis membujur yang dimuka. Tanduk letaknya pada garis membujur di belakang. Pangkal telinga letaknya lurus dengan garis mata pada garis lintang yang di atas. Balok kayu untuk kepala singa berukuran antara panjang, lebar, dan tinggi berbanding: $3: 2: 2$. Pada bidang samping kayu ditarik pula dua garis sejajar yang membujur dan dua garis sejajar yang melintang. Perpotongan garis menentukan bagian-bagian kepala. Ujung mata letaknya pada perpotongan garis melintang yang di atas dengan garis membujur yang dimuka. Pangkal telinga letaknya lurus dengan letak mata dan ujung hidung. Lebar mulut lurus kebawah dengan sudut mata. Kepala petulangan bentuk-bentuk lainnya hampir sama dengan petulangan bentuk lembu dan singa. Seperti petulangan bentuk menjangan mengikuti perbandingan petulangan bentuk lembu. Dibedakan moncongnya lebih kurus dan agak memanjang sehingga berkesan lebih langsing.

Petulangan bentuk singa kaang, macan, naga kaang, gedarba, bentuk dan ukurannya hampir sama dengan petulangan singa. Singa kaang wajahnya mirip singa, sedangkan petulangan macan mirip wajah harimau dan naga kaang sebagai wajah kepala ular besar atau patung naga sebagai penghias bangunan di Bali. Petulangan bentuk sudang-sudangan dan gajah mina, keduannya stilisasi bentuk ikan. Sudang-sudangan berkepala ikan dengan gigi dan taring yang tajam, sedangkan gajah mina, ikan berkepala gajah, dengan belalai serta gigi yang datar dan sirip ekor.

Ukuran dan bentuk kaki petulangan disesuaikan dengan panjang badan. Kalau panjang badan 5 x $40 \mathrm{~cm}$, maka panjang kaki 2 x $40 \mathrm{~cm}$, untuk kaki bagian belakang. Sedangkan kaki muka $10 \mathrm{~cm}$ lebih panjang dari kaki belakang. Kaki muka bentuknya agak lurus dan kaki belakang agak bengkok pada siku kaki. Anatomi dan proporsinya disesuaikan dengan bentuk binatang sapi untuk petulangan lembu dan petulangan singa disesuaikan dengan bentuk anjing. Petulangan singa ada pebedaan anatomi perut, yaitu perut petulangan lembu cembung agak ketengah dan petulangan singa cembungnya agak kemuka. Proporsi dan anatomi jenis petulangan lainnya seperti: petulangan bentuk macan, menjangan, naga kaang, gedarba dan lainnya disesuaikan dengan bentuk binatangnnya. 
Bentuk-Bentuk Petulangan... (I Dewa Made Pastika)

\section{Hiasan dan bahan-bahan}

Hiasan dalam berbagai motifnya dapat memperindah suatu bentuk karya seni agar lebih menarik. Sedangkan bahan-bahan adalah untuk mengungkapkan berbagai macam ide dalam menciptakan karya seni. Disamping memperindah hiasan juga dapat memperkuat bentuk dan anatomi petulangan. Beberapa jenis hiasan petulangan secara umum adalah sebagai berikut.

1. Hiasan takep pala dan takep piah ialah hiasan yang berfungsi menentukan batas antara badan dan kaki. takep pala antara badan dan kaki muka dan takep piah antara badan dan kaki belakang. Hiasan berbentuk stilisasi daun pakis (paku liking). Bahan dari kertas emas (prasban) dengan benang sebagai kontournya.

2. Hiasan pengampad ialah hiasan dari kertas emas dan pinggirannya dengan untaian benang warna warni. Dipakai menghias pada bagian kaki, punggung, ekor dan badan.

3. Hiasan badong ialah hiasan dari kertas emas, diukir tembus dengan motif patra punggel bentuknya seperti hiasan badong pada barong ket.

4. Hiasan cundang, hiasan stilisasi bentuk daun, dibuat dari kertas emas dengan pinggiran benang warna-warni. Untuk hiasan kepala, diantara kedua kening.

5. Hiasan takep jit atau hiasan tutup pantat, bentuk seperti hiasan badong, ukuran lebih kecil

Beberapa jenis hiasan petulangan khusus petulangan singa, singa kaang, dan naga kaang adalah sebagai berikut

1. Hiasan bentuk api terdiri dari: bok api, hiasan terang, kilat, teteh, dan lidah api, bentuknya hampir sama berbeda besarnya sesuai dengan penempatannya. Bok api dan kilat letaknya di kepala, hiasan terang terletak di atas kening (alis), hiasan teteh dan lidah api masing-masing pada ujung bibir dan rongga mulut menjulur keluar.

2. Hiasan gunala stilisasi dari bentuk daun pakis (paku liking) letaknya pada bagian leher kiri dan kanan sedangkan ujungnya disatukan.

3. Hiasan kuer, bentuk seperti paku liking ukurannya lebih besar, ukiran tembus motif patra punggel. Letaknya di samping kiri dan kanan leher bagian bawah.

4. Hiasan sayap, bentuk seperti sayap burung, dibuat dari kertas karton dilapis dengan kertas berwarna kombinasi dengan kapas berbagai warna. Letaknya di samping kiri kanan badan bagian muka.

5. Hiasan karang guak stilisasi bentuk kepala burung, ukiran tembus motif patra punggel, untuk hiasan pangkal ekor.

6. Hiasan dure, bentuk daun ukiran tembus dengan motif patra punggel, untuk hiasan pada punggung.

7. Hiasan dinding api, berbentuk dinding untuk melindungi api dari embusan angin. Dinding api dihiasai dengan motif ukiran dari kertas atau lukisan dengan tema pragmen suatu ceritera perjalanan roh kesorga.

8. Petulangan berbentuk gajah mina dan sudang-sudangan keduannya hampir sama yaitu hiasan bentuk sisik ikan, hiasan tatahan motip emas-emasan dan hiasan geometris lainnya. Seperti juga pada hiasan bentuk gerombong polos atau tabla dengan hiasan geometris atau hiasan lainnya.

Bahan-bahan petulangan terdiri dari: 
Bentuk-Bentuk Petulangan... (I Dewa Made Pastika)

1. Kayu sebagai bahan utama pembuatan petulangan, terutama untuk kepala, badan, kaki dan alasnya. Dengan bahan kayu sebagai bahan utama maka konstruksi dapat lebih kuat. Menurut para undagi, kayu yang baik untuk petulangan ialah kayu sandat, kayu randu atau kapuk. Kayu jenis ini tidak terlalu keras dan mudah dikerjakan. Dan mengandung air, maka sangat tahan lama saat pembakaran.

2. Bahan bambu sebagai bahan tambahan selain kayu. Bambu biasanya dipakai untuk anyaman membentuk bagian perut yang agak besar. Sifat bambu kuat, lemas dan mudah dilengkungkan, dapat dianyam. Bambu juga dapat dipakai untuk usungan.

3. Kain adalah bahan untuk membalut seluruh bagian petulangan, dari kepala, badan dan kaki. Kain yang baik untuk itu adalah kain beludru, kain sepatu, kain planel (kain panas). Sifat kain, lemas, kuat tak mudah robek dan berbulu sangat cocok untuk tekstur kulit binatang. Warnanya dapat disesuaikan dengan kebutuhan, misalnya putih, hitam atau merah.

4. Kertas ada bermacam-macam, ada kertas emas yang kuning warnanya, kertas warna-warni dan kertas bekas. Kertas kuning emas untuk berbagai hiasan tatahan dan berwarna untuk hiasan tempelan, sedangkan kertas bekas dipakai untuk lapis bagian dalam, sebelum ditutup dengan kain. Bahan ini dapat diolah dalam membentuk anatomi plastis petulangan.

5. Ijuk adalah untuk bahan isian dalam membentuk anatomi plastis. Fungsinya sama dengan kertas bekas. Di samping itu ijuk yang halus seratnya dipakai untuk rambut petulangan singa dan bulu ekor petulangan lembu.

6. Benang dipakai untuk susunan warna pada lingkaran mata, susunan warna pada pengampad dan susunan warna pada garis tepi tatahan atau ukiran. Benang yang baik untuk menghias petulangan (ngodi), adalah benang katun dalam berbagai warna. Benang jenis ini kuat dan tidak licin, sangat mudah menempel di kertas.

7. Karton, dipakai untuk alas kertas emas yang ditatah atau diukir. Karton dapat juga dipakai untuk sayap petulangan singa dan keperluan lainnya.

8. Akar pakis, berwarna hitam kriting. sangat baik untuk rambut petulangan singa.

9. Lem sebagai bahan perekat yang baik adalah lem fox. Sangat kuat daya rekatnya dan tidak tampak kotor setelah kering. Pada jaman dahulu sebelum dikenal lem fox dipakai lem dari tepung kanji, atau lem dari ketupat ketan digiling sampai lumat.

10. Kawat, adalah bahan tambahan yang biasa dipakai pada bagian dalam petulangan. Gunanya untuk menahan jenasah agar tidak jatuh keluar pada waktu pembakaran.

11. Paku sangat diperlukan untuk pemasangan kain pembalut, terutama pada bagian kepala yang pemasangannya tidak menggunakan lem, untuk menghindari kesan kotor karena tetesan lem.

\section{Pewarnaan}

Pewarnaan petulangan tidak menggunakan warna-warna khusus seperti cat atau jenis lainnya. Warnanya langsung dari jenis warna bahannya. 
Seperti warna badan petulangan ditentukan oleh warna kain penutup badan. Kain warna hitam untuk petulangan lembu hitam, warna kain putih untuk petulangan lembu putih, warna kain merah untuk petulangan singa dan lainlainnya. Demikian pula warna benang terdiri dari warna: hitam, biru, ungu, oranye, kuning dan putih. Benang dipakai mewarnai pinggiran tatahan atau ukiran, mewarnai lingkaran mata, mewarnai bibir dan sebagai warna pengampad. Susunan warna dimulai dari dari warna gelap ke warna terang, sesuai dengan urutan sigar mangsi pada lukisan tradisional Bali, atau sebaliknya. Susunan warna benang pada mata mempunyai susunan tersendiri.

Pemasangan benang dimulai dari pusat lingkaran mata dengan benang hitam sampai sepertiga lingkaran mata. Selanjutnya berturut-turut dengan benang ungu, kemudian dengan benang merah, oranye, kuning, masing-masing tiga kali lingkaran. dan ditutup dengan benang putih satu kali lingkaran. Dari benang putih itu dilanjutkan kembali dengan benang berturut-turut: warna, kuning, oranye, merah, ungu masing-masing dua kali lingkaran, dilanjutkan dengan warna hitam dan ungu satu kali lingkaran. Sisa bulatan mata dipasang benang putih sampai kesudut mata. Dan benang merah sebagai pinggirannya. Warna bibir dengan benang merah dikombinasi dengan benang oranye. Tanduk petulangan lembu dibalut dengan kertas emas warna kuning yang diremas untuk memperoleh tektur yang lembut. Rambut petulangan bentuk singa berwarna hitam yang muncul dari bahan alam yaitu akar pakis. Warna sayap berasal dari berbagai jenis warna kapa dan dikombinasi dengan kertas emas atau prasban. Sedangkan ornamen lainnya dengan kertas berwarna.

\section{Tijauan Estetis dan Artistik}

Karya petulangan di samping fungsinya sebagai tempat pembakaran juga memiliki nilai-nilai keindahan dalam seni. Pembuatan petulangan merupakan suatu pengorganisasian atau susunan elemen-elemen bentuk, permukaan dan masa yang muncul dari berbagai jenis ornamen, warna hingga mewujudkan karya yang utuh dan harmonis menghasilkan sensasi yang menyenangkan. Sedangkan ketiadaan susunan akan menyebabkan ketidakpuasan, kekecewaan dan kemuakan. Perasaan atas hubungan-hubungan adalah perasaan keindahan sedangkan sebaliknya ialah perasaan ketidakbaikan. Tidak jauh berbeda dengan karya seni lainnya bahwa pembuatan petulangan didukung oleh rasa kesenangan yang dihubungkan dengan rasa keindahan, menyangkut bentuk, hiasan, pewarnaan serta jenis materialnya. Untuk menilai keindahan bentuk petulangan dapat dilihat dari bentuk secara keseluruhan atau global, menyangkut perbandingan antara bagian-bagian, seperti kepala dengan badan, badan dengan kaki dan lainnya. Untuk itu penting diperhatikan oleh seorang sangging petulangan tentang ukuran.proporsi dan anatomi, untuk bisa mencapai kesempurnaan karya. Sebagaimana yang disebutkan 
dalam estetika barat bahwa seniman bila berkarya dapat menilai kesempurnaan karya berdasarkan rasa proporsi dan ukuran (measure).

Seniman apabila ingin berkarya sebaik-baiknya harus mengetahui dasar-dasar ukuran. Dan bagi setiap seni adalah seni mengukur, tanpa adanya ini tidak mungkin adanya seni. Seorang sangging di Bali menentukan ukuran bangunan dan prorporsinya berdasarkan lontar Asta Kosala Kosali. Lontar ini memuat petunjuk-petunjuk membuat bangunan mulai dari cara waktu penebangan kayu, merancang bangunan serta pelaksanaan upacaranya. Satuan ukuran yang disebut dalam lontar tersebut diambil dari ukuran anggota badan dengan istilah: depa, asta, lengkat, cengkang, musti sangga, nyari, guli madu, leklet. Istilah ini menentukan ukuran panjang dari suatu bentuk dan petunjuk-petunjuk ini sangat ditaati oleh para sangging dan undagi dan dipercaya dengan mengikuti petunjuk tersebut akan mengha-silkan karya indah dan berjiwa. Disamping ukuran yang telah disebutkan di atas ada pula istilah pengurip. Pengurip adalah petunjuk yang terbuka bagi sangging untuk menambah atau mengurangi dari ukuran yang telah ditentu-kan dengan maksud memenuhi selera dari para sangging yang mengerjakan karya seni. Ukuran perbandingan yang umum di Bali ialah ukuran yang disebut: a bah bangun. A bah bangun adalah ukuran perbandingan yang digunakan untuk mengukur panjang dan lebar sebuah bangunan atau bentuk sebuah karya seni. Panjang atau tinggi sebuah bentuk sama dengan diagonal dari bentuk bujur sangkar dari lebar atau dasar bangunan. Jenis perbandingan ini ada persamaan dengan fungsi dan proporsi geometris dari jaman $\mathrm{Yu}$ nani Kuno di Eropah yang disebut: The Golden Section. The Golden Section itu digunakan untuk menentukan perbandingan antara pajang dan le-bar sebuah pintu, pigura, serta buku-buku atau majalah. Malahan konon biola yang baik juga mengikuti hukum itu. Salah satu hukum The Golden Section menyebutkan memotong garis tertentu sehingga perbandingan potongan yang pendek dengan yang panjang sama dengan yang panjang dengan seluruh garis itu. Menurut hukum itu potongan garis yang dimaksud kurang lebih berbanding $2: 3$ sama dengan, $5: 8$ sama dengan $8: 13$, sama dengan, $13: 21$ dan seterusnya.

Ukuran a bah bangun di Bali dapat dipakai menentukan perbandingan antara, panjang, lebar dan tinggi ukuran kepala petulangan. Seperti kepala petulangan singa adalah: $3: 2: 2$. sedangkan ukuran kepala petulangan lembu: $2: 1: 1$. Panjang dan tinggi petulangan dengan perbandingan: 1 : 1 yang disebut perbandingan yang sama (amrepatan). Ukuran perbandingan ini adalah ukuran yang dianggap paling ideal dan indah selama ini. Dengan mengikuti perbandingan itu disertai dengan cita rasa yang tinggi akan tercipta karya petulangan yang mengandung unsur keindahan bentuk dan proprsi yang sempurna yang bersumber pada keindahan alam. Keindahan ini rupanya masih dibayangi oleh keindahan klasik yang memandang bahwa nilai keindahan tertinggi ialah berbentuk sempurna, berproporsi sempurna, 
mulia dan tenang yang merupakan bentuk idealis dari bentuk manusia (Herbert Read, 1971:8).

Hiasan petulangan, ukurannya disesuaikan penempatannya dengan bentuk petulangan-nya. Unsur-unsur hiasan berfungsi untuk menambah keindahan dengan mengikuti kaedah ornamen yang ditempatkan secara serasi pada bagian tertentu hingga dapat menambah keindahan dan memperkuat bentuk. Hiasan takep pala dan takep piah ditempatkan di antara badan dan paha, dapat memperkuat bentuk badan dan paha. Fungsi lain hiasan ini ialah menciptakan keseimbangan antara bagian-bagian dengan bagian lainnya, seperti pada hiasan badong pada leher, hiasan takep jit (tutup pantat), dan kuer. Hiasan badong yang digantungkan di leher, diperhatikan tingginya agar leher tetap baik kelihatan dan tidak tertutup. Demikian pula hiasan lainnya pemasangan harus memperhatikan ukuran, sehingga pengaruh kontrastik dapat diserasikan. Di samping keindahan bentuk proporsi anatomi dan hiasan keindahan warna, tekstur sangat penting juga. Hubungan antara warna kain pembalut petulangan dengan kertas emas yang sangat mengkilap menimbulkan kesan yang kontras. Kesan kontras kedua warna itu dapat dinetralisir dengan benang sebagai pinggiran bentuk hiasan (pengampad) di sampingnya. Benang dari bahan katun selain sebagai pinggiran ukiran, dipakai pada lingkaran mata. Lingkaran mata tampak membulat dengan pancaran yang terang dan tajam memberikan kesan lebih hidup pada petulangan. Hiasan tanduk pada petulangan lembu hanya dibalut dengan kertas emas yang diremas, dengan guratan yang melingkar-lingkar mirip dengan guratan tanduk sapi, menimbulkan tekstur terpecah, memancarkan sinar berkelipkelip sebagai kilauan batu permata. Hiasan lain, rambut petulangan bentuk singa dari bahan alami yaitu akar pakis. Tampak berombak, warna hitam lembut alami tanpa ada tambahan bahat cat, berkesan menyatu dengan warna bok api dari kertas prasban (kertas emas), dengan warna pembalut petulangan dan dengan warna benang, menimbulkan warna yang serasi. Semua hiasan yang terdiri dari berbagai material, warna dan tekstur yang berbeda, setelah berada dalam bentuk petulangan, merupakan satu kesatuan yang harmonis, mengan-dung nilai estetitik dan artistik tersendiri yang menarik perhatian bagi masyarakat.

\section{SIMPULAN}

Upacara pembakaran mayat di Bali, dikenal dengan istilah ngaben /pelebon diperlukan sarana upacara seperti wadah/bade dan petulangan. Bade bangunan dengan atap bertingkat tingkat, untuk tempat jenasah pada pada waktu diusung ke kuburan. Sedangkan petulangan untuk tempat jenasah yang akan dibakar. Berbentuk binatang seperti lembu, singa, naga kaang, macan, gedarba, sudang-sudangan dan ada juga berbentuk peti/tabla. 
Pemakaiannya disesuaikan dengan kasta/warga, sekte yang dianut leluhurnya yang ada dalam masyarakat tersebut.

Karya seni petulangan memenuhi unsur-unsur kesenirupaan, seperti hukum-hukum perbandingan dan proporsi anatomi. Hukum perbandingan panjang dan tinggi petulangan adalah: $1: 1$. Perbandingan antara panjang, lebar dan tinggi kepala lembu berbanding $2: 1: 1$. Sedangkan untuk kepala singa, perbadingan antara panjang, lebar, dan tinggi berbanding $3: 2: 2$. Tinggi ekor sama dengan tinggi kepala dan tinggi tanduk lembu sama dengan panjang kepala. Pewarnaan petulangan mengikuti warna bahan-bahannya, seperti kertas dengan berbagai warna dan warna alam diperoleh dari akar paku dan ijuk yang hitam warnanya. Teknik pembuatan petulangan melalui tiga tahap, yaitu: 1) memakuh (membuat rangka atau rancangan), 2) membalut (nukub), menutup rangka petulangan dengan kain sesuai dengan warna yang telah ditentukan, seperti kain putih, hitam, merah dan lainnya, 3) ngodi (menghias bagian-bagian petulangan dengan memperhatikan komposisi, pewarnaan dan kerapian). Keharmonisan warna dan variasi tekstur dan bahan akan menentukan terwujudnya petulangan yang indah dan menarik.

\section{DAFTAR RUJUKAN}

. 1978. Parisada Hindu Dharma, Upadesa, Tentang ajaran Agama Hindu.

Sunjoyo, Drs. 1976. Diktat Kuliah Tinjauan Seni. FT Arsitektur Institut Teknologi 10 Nopember Surabaya

. Lontar Denpasar, Koleksi Mangku Jero Kuta, Sesetan Denpasar.

. Babad Pasek, Koleksi Ida Pedanda Manuaba, Griya Anyar Padangtegal, Ubud.

. Babad Dalem Katiagan, Koleksi I Ketut Rinda, Br. Tengah Blahbatuh, Gianyar.

Covarrubias, Maguel.1972, Island Of Bali, Oxford University Press.

Goris, Dr. R., Bali Atlas Kebudayaan, Cults and Customs, Diterbitkan oleh Pemerintah Republik Indonesia.

Herbert Read, Pengantar Seni, bagian pertama dan kedua diterjemahkan oleh Soedarso SP.MA Dosen ASRI Yogyakarta.

Kadir, Abdul MA. Pengantar Aesthetica. Sekolah Tinggi Seni Rupa Indonesia ASRI Yogyakarta.

Van Der Hoop, An. J. Th. A. Th.,1949, Ragam-ragam Perhiasan Indonesia. Uitgegeven door het Koninklijk Bataviasch Genootschap van Kunsten en Wetenschappen.

Zimmer Henrich, Myths and Symbols in Indian Art and Civilization, Edited by Joseph Cambeel. 